\title{
Outcomes after surgical resection of cardiac sarcoma in the multimodality treatment era
}

\author{
Faisal G. Bakaeen, MD, ${ }^{a}$ Dawn E. Jaroszewski, MD, ${ }^{\mathrm{a}, \mathrm{b}}$ David C. Rice, MD, ${ }^{\mathrm{b}}$ Garret L. Walsh, MD, ${ }^{\mathrm{b}}$ Ara A. Vaporciyan, MD, \\ Steven S. Swisher, MD, ${ }^{\mathrm{b}}$ Robert Benjamin, MD, ${ }^{\mathrm{b}}$ Shanda Blackmon, MD, ${ }^{\mathrm{b}, \mathrm{c}}$ and Michael J. Reardon, $\mathrm{MD}^{\mathrm{b}, \mathrm{c}}$
}

Objective: Primary cardiac sarcomas are rare tumors carrying poor prognosis. Resection remains the primary therapy. Especially in recent years, chemotherapy and radiation have been used adjunctively.

\begin{abstract}
Methods: All patients $(n=27)$ surgically treated for primary cardiac sarcoma at two tertiary referral centers from January 1990 to January 2006 were retrospectively reviewed.

Results: There were 13 women and 14 men, with 26 resections and 1 palliative debulking performed. Cardiac explantation was necessary in 8 cases because of tumor location. Concomitant valve surgery (repair or replacement) or coronary artery bypass grafting was performed in 9 and 3 patients, respectively. Synchronous or staged resections of associated pulmonary metastases were performed in 6 and 2 patients, respectively. Operative mortality was $7.4 \%$ (2/27). Preoperative or postoperative chemotherapy was administered to 16 and 19 patients, respectively. At follow-up (median 22 months, range, 2-119 months), 12 patients were alive, with 7 tumor free. Among patients who underwent resection with curative intent and survived surgery $(n=24)$, median survival was 23.5 months (range 4-119 months). Patients who underwent surgical resection, radiofrequency ablation, or radiation treatment for tumor recurrence (local or metastatic, $n=7$ ) had median survival of 47 months (range 16-119 months), whereas patients with no further intervention for recurrent disease $(\mathrm{n}=7)$ had median survival of 25 months (range 8-34 months).
\end{abstract}

Conclusions: Multimodal therapy can achieve reasonable survival for patients with resected cardiac sarcomas. Patients with local tumor recurrence or metastatic disease may still benefit from aggressive treatment.

Primary malignant tumors of the heart and great vessels are extremely rare. Sarcoma represents more than two thirds of these malignancies and usually has an aggressive and fatal course. ${ }^{1,2}$ The bleak prognosis of this disease has been reported in several small case series and individual reports. ${ }^{3-10}$

Our institution's review of 21 patients treated from 1964 to 1989 reiterated the poor prognosis of the disease, with a median survival of only 11 months. ${ }^{11}$ A survival advantage was noted for patients who underwent aggressive surgical resection and clearing of all disease relative to those who received palliative treatment (median 24 vs 10 months). ${ }^{11}$

More recently, a collaborative effort between The University of Texas M. D. Anderson Cancer Center and the Methodist Hospital has been adopted. This new treatment includes surgical resection with adjunctive chemotherapy and radiation therapy. We review our evolving experience with aggressive multimodality treatment of cardiac sarcomas.

From the Baylor College of Medicine, ${ }^{\mathrm{a}}$ M. D. Anderson Cancer Center, ${ }^{\mathrm{b}}$ and Methodist DeBakey Heart and Vascular Center, ${ }^{\mathrm{c}}$ Houston, Tex.

Received for publication Aug 11, 2008; revisions received Oct 28, 2008; accepted for publication Nov 18, 2008.

Address for reprints: Faisal G. Bakaeen, MD, Department of Cardiothoracic Surgery, Baylor College of Medicine, One Baylor Plaza, Houston, TX, 77030 (E-mail: fbakaeen@bcm.edu).

J Thorac Cardiovasc Surg 2009;137:1454-60

$0022-5223 / \$ 36.00$

Copyright (c) 2009 by The American Association for Thoracic Surgery doi:10.1016/j.jtcvs.2008.11.026

\section{MATERIALS AND METHODS Patients}

With institutional review board approval and with waiver of individual consent granted, a retrospective review was performed of all patients who underwent surgical treatment of cardiac sarcoma from January 1990 to January 2006. All patients with histologically proven primary sarcoma involving cardiac chambers or great vessels were included. All patients were seen by the senior author (M.J.R.). Patients who were referred for surgery but turned down, estimated by M.J.R. to be $20 \%$ of referrals, were not included in our database.

Patient charts were reviewed to document data on presenting symptoms, preoperative workup, surgical and oncologic treatment, tumor pathologic type, hospital course, and complications. Operative mortality was defined to encompass any death occurring during the first 30 postoperative days or during the same hospitalization. After hospital discharge, a multidisciplinary team closely followed up patients, unless the patient opted to be followed up closer to home with guidance from our institution. Follow-up data to January 2006 or death were available for all patients.

\section{Evaluation and Multimodality Treatment}

Patients underwent a thorough review by a multidisciplinary team, including medical oncologists, radiation oncologists, and cardiac surgeons. Computed tomography, cardiac gated magnetic resonance imaging, and echocardiography were the primary imaging modalities used by the operating surgeon to determine anatomic resectability. Positron emission tomography and coronary angiography were performed in a selective manner.

The overall treatment plan, including the timing of various therapy modalities, was based on a number of tumor- and patient-related factors including resectability, tumor susceptibility to chemotherapeutic agents, disease-free interval in cases involving recurrence, the presence and severity of symptoms, and the physiologic status of the patient. For the purposes of this study, complete resection was defined as an absence of gross residual disease after resection (R0/R1). Incomplete resection was defined as the presence of macroscopic residual disease (R2) after resection. 


\section{Statistical Analysis}

All data were analyzed with SAS version 8.1 (SAS Institute, Inc, Cary, NC). Continuous variables are reported as median and range (minimum to maximum). Estimate of overall survival was also calculated by the KaplanMeier method and expressed as percentage with $95 \%$ confidence interval.

\section{RESULTS}

\section{Patient Profile}

Between January 1990 and January 2006, a total of 27 patients underwent surgical resection for primary cardiac sarcomas. There were 13 women and 14 men, with a median age of 40.6 years (range 18-69 years). Signs and symptoms included dyspnea in 24 patients $(89 \%)$, arrhythmias or palpitations in $14(52 \%)$, cough in $11(41 \%)$, chest pain in 8 $(30 \%)$, and constitutional symptoms of fever, weight loss, or night sweats in $12(44 \%)$. Symptomatic pericardial effusion was present in 5 patients $(19 \%)$.

Seventeen patients $(63 \%)$ had undergone previous surgical procedures at outside institutions. The median time from previous procedure to definitive surgical treatment was 7 months (range $1-10$ months).

\section{Tumor Characteristics}

The tumors were grouped according to three anatomic locations: right heart sarcomas in 17 patients $(63 \%)$, left heart sarcomas in $8(30 \%)$, and pulmonary artery sarcomas in 2 $(7 \%)$. Two patients $(7.5 \%)$ had multiple tumor foci, including 3 foci in the right atrium and right ventricle in 1 patient, and 3 foci in the left atrium and interventricular septum in another patient. Histologic types included angiosarcoma in 11 patients $(41 \%)$, undifferentiated high-grade sarcoma in $7(26 \%)$, malignant fibrous histiocytoma in $4(15 \%)$, leiomyosarcoma in $2(7 \%)$, synovial cell sarcoma in $2(7 \%)$, and chondroblastic high-grade osteosarcoma in $1(4 \%)$.

\section{Surgery}

Median sternotomy and total cardiopulmonary bypass with bicaval venous cannulation and aortic arterial return were used in most cases. Two patients $(7 \%)$ required hypothermic circulatory arrest for resection of right atrial tumors with extensive involvement of the superior vena cava (Table 1). Cardiac explantation with autotransplantation was used in 8 patients $(30 \%)$ because of extensive left atrial involvement, as previously described. ${ }^{12,13}$ Reconstruction of cardiac chambers was performed with bovine pericardium. Great vessel repair or reconstruction was performed with bovine pericardium in 7 patients $(26 \%)$, autologous pericardium in $4(15 \%)$, Dacron polyester fabric or polytetrafluoroethylene interposition grafts in $2(7 \%)$, and cryopreserved pulmonary artery allograft in $1(4 \%)$. Involvement of the right coronary artery occurred in 3 patients $(11 \%)$ and required concomitant coronary artery bypass grafting. Mitral and tricuspid repairs or replacements were performed in 8 patients $(30 \%)$. One patient underwent palliative debulking
TABLE 1. Surgical procedures performed at our institution

\begin{tabular}{lr}
\multicolumn{1}{c}{ Surgery } & Patients \\
\hline Extent of resection & 15 \\
R0 & 11 \\
R1 & 1 \\
R2 & \\
Surgical approach and associated procedures & 8 \\
Explantation or reimplantation & 2 \\
Hypothermic circulatory arrest & 3 \\
Coronary artery bypass grafting & 14 \\
Great vessel repair or reconstruction & 9 \\
Valve repair or replacement & 4 \\
Tricuspid & 4 \\
Mitral & 1 \\
Pulmonary root & 6 \\
Concomitant pulmonary resection & 2 \\
Pneumonectomy & 3 \\
Lobectomy & 1 \\
Wedge resection & 1 \\
Staged pulmonary resection & 2 \\
Bilobectomy & 1 \\
Wedge resection & 1 \\
\hline
\end{tabular}

only because of extensive tumor involvement of the right atrium and invasion into the posterior mediastinum. The specific operative procedures performed in each individual case are outlined in Table 2.

\section{Additional Pulmonary Resections}

Eight patients $(30 \%)$ had known pulmonary metastases at the time of definitive cardiac resection. Five of these patients underwent concomitant resection, and another 2 patients underwent staged resections at a later date (Table 2). The remaining patient (patient 11) had rapid progression of his pulmonary metastases after cardiac resection and did not undergo additional surgery. The two patients with pulmonary artery sarcomas required pneumonectomy to achieve R0 resection. One patient (patient 22) underwent cardiac autotransplantation to treat to a sarcoma involving the left atrium, the left pulmonary veins, and hilum. A return to the operating room was necessary for pneumonectomy because of a devitalized left lung.

\section{Morbidity and Mortality}

There were 2 perioperative deaths $(7 \%)$. One patient (patient 17) who had undergone extensive resection of the right ventricle, replacement of the tricuspid valve, and distal septal resection, died of irreversible coagulopathy and cardiac failure on the first postoperative day. This patient had a history of chest wall radiation for lymphoma and breast cancer. The second patient (patient 15) died on postoperative day 18 of sepsis and multiple organ failure after extensive cardiac 
TABLE 2. Tumor histologic type, location, and definitive surgical procedures

\begin{tabular}{|c|c|c|c|c|}
\hline Case & $\begin{array}{c}\text { Histologic } \\
\text { type }\end{array}$ & Primary site & $\begin{array}{c}\text { Metastasis at } \\
\text { presentation }\end{array}$ & Resection margin and operative features \\
\hline \multicolumn{5}{|c|}{ Right heart sarcomas } \\
\hline 1 & Angiosarcoma & RA & Lung & $\begin{array}{l}\mathrm{R} 1 \text { resection; RA reconstruction; bilobectomy } 1 \text { mo } \\
\text { later }\end{array}$ \\
\hline 2 & Angiosarcoma & RA & None & $\begin{array}{l}\mathrm{R} 0 \text { resection; RA, SVC reconstruction; TV } \\
\text { annuloplasty }\end{array}$ \\
\hline 3 & Angiosarcoma & RA & None & R0 resection \\
\hline 4 & MFH & RA & Lung & R0 resection, right lung wedge $\times 2$ \\
\hline 5 & HGUS & RA, right PA & Lung & $\begin{array}{l}\text { R0 resection; RA, PA reconstruction; wedge } \\
\text { resection } \times 3 \text { lesions and RFA } \times 2 \text { lesions in right } \\
\text { lung } 6 \text { mo later }\end{array}$ \\
\hline 6 & Leiomyosarcoma & RA, SVC, BCV & None & $\mathrm{R} 1$ resection; RA, SVC, BCV reconstruction \\
\hline 7 & Synovial sarcoma & RA, SVC & None & Palliative debulking \\
\hline 8 & Angiosarcoma & RA, extension into RCA & None & $\mathrm{R} 1$ resection; RITA to RCA bypass \\
\hline 9 & Angiosarcoma & RA, TV & None & R0 resection; TV replacement \\
\hline 10 & Synovial sarcoma & $\mathrm{RA}$, extension into right superior $\mathrm{PV}$ & None & $\mathrm{R} 0$ resection; hypothermic circulatory arrest \\
\hline 11 & Angiosarcoma & RA, SVC & Lung & $\mathrm{R} 0$ resection; RA, SVC reconstruction \\
\hline 12 & Angiosarcoma & RA, RV, SVC & None & R0 resection; SVC reconstruction \\
\hline 13 & Angiosarcoma & RA, SVC, LA roof & None & $\mathrm{R} 0$ resection; SVC, atrial reconstruction \\
\hline 14 & Angiosarcoma & RA, SVC, RCA & None & $\begin{array}{l}\text { R0 resection; RCA reconstruction with RITA } \\
\text { interposition graft }\end{array}$ \\
\hline 15 & Angiosarcoma & RA, SVC, extension into RV, RCA & Lung & $\begin{array}{l}\text { R1 resection; hypothermic circulatory arrest; SVG to } \\
\text { PDA coronary bypass; RUL wedge resection }\end{array}$ \\
\hline 16 & HGUS & $\begin{array}{l}\text { RA, TV, extension into RV,IVS } \\
\quad \text { (3 separate tumor foci) }\end{array}$ & None & $\begin{array}{l}\text { R1 resection; cardiac explantation; TV excision, } \\
\text { replacement }\end{array}$ \\
\hline 17 & HGUS & RV, TV, IVS & None & R0 resection; TV excision, replacement \\
\hline \multicolumn{5}{|c|}{ Left heart sarcomas } \\
\hline 18 & MFH & LA & Lung & $\mathrm{R} 0$ resection; RUL resection \\
\hline 19 & HGUS & LA & None & $\mathrm{R} 1$ resection; cardiac explantation \\
\hline 20 & HGUS & LA, left superior PV & None & $\begin{array}{l}\text { R1 resection; cardiac explantation; LA, PV } \\
\text { reconstruction }\end{array}$ \\
\hline 21 & HGUS & LA, right PVs & None & $\mathrm{R} 1$ resection; cardiac explantation \\
\hline 22 & MFH & LA, left PVs, hilum & None & $\begin{array}{l}\text { R1 resection; cardiac explantation; LA, left PVs } \\
\text { reconstruction; MV repair }\end{array}$ \\
\hline 23 & HGUS & LA, IVS (3 separate tumor foci) & None & $\begin{array}{l}\text { R1 resection; cardiac explantation; MV resection, } \\
\text { replacement }\end{array}$ \\
\hline 24 & MFH & LA, MV annulus & Lung & $\begin{array}{l}\text { R1 resection; cardiac explantation; MV excision, } \\
\text { replacement; RUL wedge }\end{array}$ \\
\hline 25 & $\mathrm{CHGO}$ & IVS, chordae of MV & None & $\begin{array}{l}\text { R0 resection; cardiac explantation; MV excision, } \\
\text { replacement }\end{array}$ \\
\hline \multicolumn{5}{|c|}{ Pulmonary artery sarcomas } \\
\hline 26 & Leiomyosarcoma & Main PA at bifurcation & Lung & R0 resection; left pneumonectomy; PA reconstruction \\
\hline 27 & Angiosarcoma & Main PA, valve & None & $\begin{array}{l}\text { R0 resection, main PA reconstruction with } \\
\text { homograft; right pneumonectomy }\end{array}$ \\
\hline
\end{tabular}

$R A$, Right atrium; $S V C$, superior vena cava; $T V$, tricuspid valve; $M F H$, malignant fibrous histiocytoma; $H G U S$, high-grade undifferentiated sarcoma; $P A$, pulmonary artery; $R F A$, radiofrequency ablation; $B C V$, brachiocephalic vein; $R C A$, right coronary artery; $R I T A$, right internal thoracic artery; $P V$, pulmonary vein; $L A$, left atrium; $R V$, right ventricle; $S V G$, saphenous vein graft; $P D A$, posterior descending coronary artery; $R U L$, right upper lobe; $I V S$, interventricular septum; $M V$, mitral valve; $C H G O$, chondroblastic high-grade osteosarcoma.

resection of a tumor involving the right atrium and ventricle, in addition to a wedge resection of a right upper lobe lesion.

Postoperative hemorrhage requiring surgical reexploration was necessary in 2 patients $(7 \%)$. Cardiac complications included mild congestive heart failure (medically treated) in 17 patients $(63 \%)$, cardiac arrhythmias in 5 $(19 \%)$, persistent complete atrioventricular block necessitat- ing a pacemaker placement in 1 patient $(4 \%)$ and pericarditis in 2 patients $(7 \%)$. Pulmonary complications included pneumonia in 4 patients $(15 \%)$ and pleural effusions requiring drainage in $8(30 \%)$. Phrenic nerve paralysis occurred in 2 patients $(7 \%)$. One patient required a reoperation at 6 weeks after his initial definitive surgery (cardiac autotransplantation) for a stricture at the superior vena cava anastomotic 
site. The median hospital stay was 11 days (range 5-65 days).

\section{Chemotherapy and Radiotherapy}

All but 1 patient received chemotherapy or radiation therapy in the preoperative or postoperative setting (Table 3). Neoadjuvant chemotherapy was administered to 16 patients $(59 \%)$ before definitive surgical management, and 19 patients $(70 \%)$ received adjuvant chemotherapy. The most common agents used were doxorubicin, ifosfamide, gemcitabine, and taxoterene. One patient received preoperative radiation therapy at an outside institution before referral for definitive surgery, and another patient received postoperative radiation therapy to the mediastinum after definitive surgical resection because of a positive (microscopic) resection margin. One patient (patient 16) died of chemotherapyrelated toxicity.

\section{Tumor Recurrence}

Three of the 26 patients who underwent $\mathrm{R} 0$ or $\mathrm{R} 1$ resection had local recurrences at 5, 16, and 46 months after surgery (Table 3). All local recurrences were in patients with R1 resections; none were in patients with R0 resections. Repeated resection was attempted in 2 patients; however, 1 patient (patient 1) had extensive involvement of the liver and underwent palliative debulking only. The other patient (patient 21) had sarcoma recurrence in the left atrium with extensive right pulmonary vein and lung involvement. This patient underwent a second cardiac explantation and R0 resection that included a right pneumonectomy.

Twelve patients had distant recurrence at a median interval of 10 months from surgery. The most common sites of distant metastases were the lungs ( 8 patients), liver (4 patients), and brain (4 patients; Table 3 ).

\section{Survival}

The 1- and 2- year survivals for the entire patient cohort $(\mathrm{n}=27)$ were $80.9 \%$ (95\% confidence interval $60 \%-$ $92 \%$ ) and $61.6 \%$ (95\% confidence interval $38 \%-78 \%$ ), respectively (Figure 1). At a median follow-up of 22 months (range 2-119 months), 44\% (12/27) remain alive. At the time of follow-up, patients who had undergone resection with curative intent (R0/R1) and survived surgery $(\mathrm{n}=$ 24) had a median survival of 23.5 months (range 4-119 months). Patients who had undergone surgical resection, radiofrequency ablation, or radiation treatment for tumor recurrence (local or metastatic, $\mathrm{n}=7$ ) had a median survival of 47 months (range 16-119 months), whereas patients with no further intervention for recurrent disease $(n=7)$ had a median survival of 25 months (range 8-34 months).

\section{DISCUSSION}

Malignant cardiac tumors are rare and usually fatal. Most are sarcomas that are highly aggressive and locally inva- sive. ${ }^{14,15}$ There are a few isolated case reports of patient survival longer than 5 years with less aggressive tumor histologic types. ${ }^{16}$ Most published series, including one from our institution evaluating outcomes from an earlier time frame, report a dismal prognosis, with fewer than half of the patients surviving at 1 year. ${ }^{3-11}$

In this series, most patients were referred with a tissue diagnosis established at the referring institution. Most left atrial sarcomas had been previously resected and thought to be myxoma before the first surgery and then incompletely removed. In fact, it can be difficult to distinguish between a sarcoma and a large myxoma. ${ }^{17}$ Most right-sided sarcomas had been sampled for biopsy through a sternotomy (when the tumor was deemed unresectable) or through a subxiphoid approach. We recently have begun to use a percutaneous catheter-based approach to obtain a diagnostic biopsy specimen for patients with tumors in a fashion similar to the biopsy technique used in our transplant population. Most left ventricular sarcomas and pulmonary artery sarcomas had the diagnosis presumed preoperatively and confirmed postoperatively.

Complete surgical resection is crucial for any hope of survival for the patient. ${ }^{5,11,18-20}$ Many patients do not undergo complete resections, partly because of the lack of experience with extended cardiac resections and partly because of uncertainty about the diagnosis at the time of the initial surgical exploration. In this study, nearly two thirds of the patients referred had undergone previous inadequate surgical interventions. Although it is technically challenging, the mainstay of treatment remains en bloc surgical excision.

Our resections were undertaken both for potential cure and for palliation. Resections for cure required that there be no evidence of metastatic disease and that the anatomy of cardiac involvement have the potential for complete resection. The entire left and right atria can be resected and reconstructed. We have found that we can resect about $30 \%$ of the right ventricle and still maintain adequate cardiac function. Left ventricular resections are possible but carry higher risk. We believe that the single area that really renders resection impossible is involvement of the fibrous skeleton of the heart. Resection for palliation may be undertaken in the presence of metastatic disease if the control with chemotherapy is thought possible.

Recently, we have found it clinically beneficial to group cardiac sarcomas by anatomic location rather than tissue type when making clinical decisions. ${ }^{21}$ Right heart sarcomas, left heart sarcomas, and pulmonary artery sarcomas represent our clinical groups.

Most right heart sarcomas are angiosarcomas and tend to be bulky. They infiltrate the cardiac muscle and metastasize to the lungs. To achieve negative margins, the entire right atrium can be resected and reconstructed with bovine pericardium. Surgical management of tumors extending to the superior or inferior vena cava requires modifications of 
TABLE 3. Multimodality treatment, tumor recurrence, and survival

\begin{tabular}{|c|c|c|c|c|c|c|}
\hline Case & $\begin{array}{c}\text { Neoadjuvant } \\
\text { therapy }\end{array}$ & $\begin{array}{l}\text { Adjuvant } \\
\text { therapy }\end{array}$ & Recurrence & $\begin{array}{l}\text { Additional } \\
\text { treatments }\end{array}$ & Status & $\begin{array}{c}\text { Survival from } \\
\text { dx (mo) }\end{array}$ \\
\hline \multicolumn{7}{|c|}{ Right heart sarcomas } \\
\hline 1 & AI & $\begin{array}{l}\text { Paclitaxel, } \\
\text { doxorubicin, DTIC, } \\
\text { gemcitabine }\end{array}$ & $\begin{array}{l}\text { Local at IVC (5 mo), } \\
\quad \text { brain }(39 \mathrm{mo})\end{array}$ & $\begin{array}{l}\text { Attempted re-resection } \\
\text { IVC (R2 at liver); } \\
\text { resection brain mets }\end{array}$ & Dead & 58 \\
\hline 2 & Paclitaxel, AI & AI, gemcitabine & Liver, brain, bone ( $8 \mathrm{mo})$ & XRT to mets & Dead & 22 \\
\hline 3 & Paclitaxel, AI & Gemcitabine & $\begin{array}{l}\text { Liver, remote } \\
\text { mediastinal }(2 \mathrm{mo})\end{array}$ & None & Dead & 8 \\
\hline 4 & None & None & None & None & Dead & 36 \\
\hline 5 & None & AI & $\begin{array}{l}\text { Lung ( } 7 \mathrm{mo}) \text {, brain } \\
\qquad(14 \mathrm{mo})\end{array}$ & $\begin{array}{l}\text { RFA of lung mets, } \\
\text { brain XRT }\end{array}$ & Dead & 24 \\
\hline 6 & Doxorubicin, DTIC & None & Lung, abdomen (9 mo) & Lung mets resection & Alive with disease & 16 \\
\hline 7 & None & None & NA & None & Dead & 3 \\
\hline 8 & AI & $\begin{array}{l}\text { Chest XRT, AI, } \\
\text { paclitaxel, imatinib, } \\
\text { gemcitabine, docetaxel }\end{array}$ & $\begin{array}{l}\text { Lung (16 mo), liver } \\
\qquad(29 \mathrm{mo})\end{array}$ & $\begin{array}{l}\text { Wedge resection of pleural } \\
\text { mets; resection } 1 \text { liver } \\
\text { mets, RFA other mets }\end{array}$ & Alive withdisease & 47 \\
\hline 9 & None & AI, paclitaxel & $\begin{array}{l}\text { Suspicious mass } \\
\text { detected by } \\
\text { computed } \\
\text { tomography }\end{array}$ & $\begin{array}{l}\text { Exploration, resection of } \\
\text { benign scar }\end{array}$ & NED & 40 \\
\hline 10 & None & None & Unknown & None & Dead & 10 \\
\hline 11 & Doxorubicin & AI & $\begin{array}{l}\text { Progression of } \\
\text { existing lung mets }\end{array}$ & None & Dead & 30 \\
\hline 12 & I, epirubicin CHOP & Paclitaxel & Brain (1 mo) & None & Alive with disease & 2 \\
\hline 13 & Gemcitabine, taxoterene & None & None & None & NED & 14 \\
\hline 14 & $\begin{array}{l}\text { Imatinib, epirubicin, } \\
\text { letrozole, gemcitabine, } \\
\text { docetaxel }\end{array}$ & Gemcitabine, docetaxel & Liver, lung (11 mo) & None & Alive with disease & 33 \\
\hline 15 & None & None & None & None & PO death & 0.5 \\
\hline 16 & AIM, gemcitabine, XRT & High-dose ifosfamide & Lung (6 mo) & None & Dead (chemotoxicity) & 25 \\
\hline 17 & None & None & None & None & PO death & 3 \\
\hline \multicolumn{7}{|c|}{ Left heart sarcomas } \\
\hline 18 & $\begin{array}{l}\text { AI, dexrazoxane with } \\
\text { growth factors }\end{array}$ & High-dose ifosfamide & None & None & NED & 27 \\
\hline 19 & Ifosfamide & AI & $\begin{array}{l}\text { LA recurrence, multiple } \\
\text { hilar mets }(16 \mathrm{mo})\end{array}$ & None & Dead & 34 \\
\hline 20 & Ifosfamide & High-dose ifosfamide & None & XRT & NED & 23 \\
\hline 21 & Ifosfamide & High-dose ifosfamide & $\begin{array}{l}\text { Cardiac recurrence with } \\
\text { extensive right } \\
\text { pulmonary vein, lung } \\
\text { involvement ( } 46 \mathrm{mo} \text { ) }\end{array}$ & $\begin{array}{l}\text { Second explantation, } \\
\text { excision of disease } \\
\text { (R0), right } \\
\text { pneumonectomy }\end{array}$ & $\begin{array}{l}\text { Death, } \\
\text { unknown cause }\end{array}$ & 119 \\
\hline 22 & $\begin{array}{l}\text { AI, immunotherapy with } \\
\text { darbapoetin alfa, } \\
\text { pegfilgrastim }\end{array}$ & None & None & None & NED & 20 \\
\hline 23 & $\mathrm{AI}$ & $\begin{array}{c}\text { Temozolomlide, } \\
\text { doxorubicin }\end{array}$ & Lung, pelvis ( $5 \mathrm{mo}$ ) & None & Dead & 16 \\
\hline & None & $\begin{array}{l}\text { High-dose ifosfamide, } \\
\text { gemcitabine, } \\
\text { interferon-gamma }\end{array}$ & None & None & Dead & 15 \\
\hline 25 & None & High-dose ifosfamide & None & None & NED & 21 \\
\hline \multicolumn{7}{|c|}{ Pulmonary artery sarcomas } \\
\hline 26 & None & AI & $\begin{array}{l}\text { Rib, vertebrae, pelvis } \\
\quad(39 \mathrm{mo})\end{array}$ & XRT to mets & Alive with disease & 75 \\
\hline 27 & None & Gemcitabine, taxoterene & None & None & NED & 11 \\
\hline
\end{tabular}

$\overline{d x}$, Diagnosis; $A I$, Adriamycin (doxorubicin), ifosfamide; DTIC, doxycycline, Taxol (paclitaxel), ifosfamide, cyclophosphamide; IVC, inferior vena cava; mets, metastasis; $X R T$, external beam radiation therapy; $R F A$, radiofrequency ablation; $N A$, not applicable; $N E D$, no evidence of disease; $C H O P$, cyclophosphamide, hydroxyrubicin, Oncovin (vincristine), prednisone; $P O$, postoperative; $A I M$, Adriamycin (doxorubicin), ifosfamide, mesna; $L A$, left atrial. 


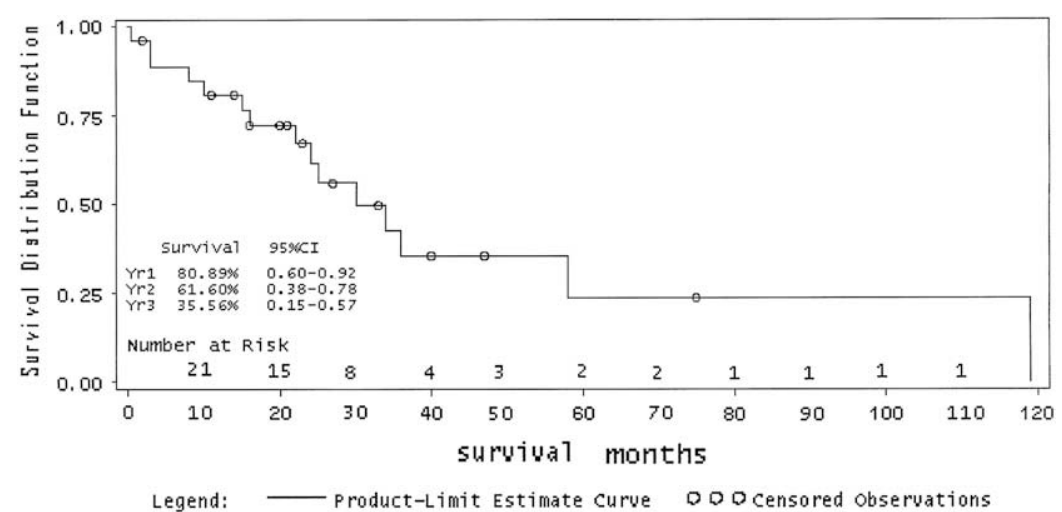

FIGURE 1. Survival of patients with surgically treated cardiac sarcoma. $C I$, Confidence interval.

cannulation technique or deep hypothermic circulatory arrest. Patients with extensive involvement of the tricuspid valve undergo valve excision and replacement. Involvement of the right coronary artery is managed by coronary artery bypass grafting or reconstruction.

In our experience, malignant fibrous histiocytomas account for many left heart sarcomas. All but 1 of the left heart sarcomas in our series required cardiac explantation, ex vivo tumor resection, and cardiac reconstruction, followed by cardiac reimplantation. Complete removal of the heart allows excellent visualization of the tumor and surrounding cardiac structures.

Pulmonary artery sarcomas tend to be angiosarcomas. Chest computed tomography and magnetic resonance imaging with contrast are the most useful imaging modalities and supersede echocardiography for defining the tumor location and extent. In the 2 cases we report here, resection required replacement of at least some of the pulmonary root and also required pneumonectomy.

The roles of radiation and chemotherapy in malignant cardiac tumors are still controversial. Because of the rarity of the disease, there are no prospective studies to determine the efficacies of chemotherapy and radiotherapy in addition to surgery. The limited experience of any single center in the treatment of cardiac sarcomas makes it difficult to evaluate the relative importance of these modalities, and extrapolations from the behavior of other soft-tissue sarcomas may not be applicable.

On the basis of limited reports, however, adjuvant chemotherapy does not appear to enhance survival for patients who have undergone incomplete resections. ${ }^{3,5,11}$ The combination of several chemotherapeutic agents appears to be more effective than single-agent therapy, with ifosfamide, doxorubicin, cyclophosphamide, and paclitaxel all being used with evidence of response. ${ }^{11,15,16,22,23}$ A review by Poole and colleagues ${ }^{3}$ has suggested that survival could be enhanced by postoperative irradiation, but patient numbers were small. Others have reported a beneficial effect from a combination of adjuvant chemotherapy and radiotherapy. ${ }^{5,15,16}$
We believe that neoadjuvant therapy would be helpful in obtaining clear margins by shrinking the tumor in most patients, although we have no proof of this. Unfortunately, most left-sided tumors are first seen with heart failure and require prompt relief, and chemotherapy does not provide this. Therefore most left-sided lesions are treated with adjuvant therapy only. Pulmonary artery sarcoma lesions usually are first seen with severe right heart failure; they also need immediate relief and are treated with adjuvant therapy only. Right heart sarcomas are first seen with a lesser degree of heart failure but are often larger, more diffuse and infiltrative than pulmonary artery or left sided sarcomas. They are therefore usually the best candidates for neoadjuvant therapy.

For recurrent cardiac sarcomas, we have adopted a strategy of aggressive treatment when the recurrence is local or if the metastatic load is limited. Reasonable survival is achievable for patients with synchronous metastases, and surgical treatment of metastatic disease may be worthwhile. Surgical resection of local recurrence may be formidable but did produce an example of long-term survival (patient 21). Radiofrequency ablation and adjuvant treatment for local recurrence or metastatic disease may also enhance survival.

In our patient cohort, the morbidity and mortality figures were significant, reflecting the magnitude and complexity of the surgical procedures. This is an important consideration when discussing the treatment plan with the patient and in the informed consent process. In addition, patients should be educated about the side effects of the various nonsurgical therapies and the potential complications. The reality is that these surgical patients tend to be relatively young but unfortunately have a rare cancer that has a poor prognosis.

\section{Limitations}

Our study is limited by the small number of patients, and therefore our findings can only serve as a guide and a contribution toward a better understanding of these rare tumors. Furthermore, many of our patients were referred from other hospitals, including international centers; some treatment 
plans, including adjuvant therapy, were therefore performed closer to home, although usually with guidance from our institution. As a result, the details of the follow-up care and treatment were not always complete.

\section{CONCLUSIONS}

With aggressive forms of surgical and multimodal therapy, long-term survival may be achieved in certain cases of cardiac sarcoma. Obtaining a complete resection should be the primary goal of the thoracic surgeon, and additional work on adjuvant therapy for biologic control of the disease is imperative. Resection and treatment of metastatic and recurrent disease should be considered when possible and may increase survival.

\section{References}

1. Raaf HN, Raaf JH. Sarcomas related to the heart and vasculature. Semin Surg Oncol. 1994;10:374-82.

2. Odim J, Reehal V, Laks H, Mehta U, Gishbein MC. Surgical pathology of cardiac tumors. Two decades at an urban institution. Cardiovasc Pathol. 2003;12:267-70.

3. Poole GV, Meredith JW, Breyer RH, Mills SA. Surgical implication in malignant cardiac disease: collective review. Ann Thorac Surg. 1983;36:484-91.

4. Molina JE, Edwards JE, Ward HB. Primary cardiac tumors: experience at the University of Minnesota. Thorac Cardiovasc Surg. 1990;38:183-91.

5. Burke AP, Cown D, Virmani R. Primary sarcomas of the heart. Cancer. 1992;69: 387-95.

6. Murphy MC, Sweeney MS, Putnam JB, Walker WE, Frazier OH, Ott DA, et al. Surgical treatment of cardiac tumors: a 25-year experience. Ann Thorac Surg. 1990;49:612-7.

7. Hattori Y, Iriyama T, Watanabe K, Negi K, Takeda I, Sugimura S. Primary cardiac sarcoma: two case reports. Jpn Circ J. 2000;64:222-4.
8. Centofanti P, Di Rosa E, Dato GM, Deorsola L, Patanè F, La Torre M, et al. Primary cardiac tumors: early and late results of surgical treatment in 91 patients. Ann Thorac Surg. 1999;68:1236-41.

9. Bakaeen FG, Reardon MJ, Coselli JS, Miller CC, Howell JF, Lawrie GM, et al. Surgical outcome in 85 patients with primary cardiac tumors. Am J Surg. 2003; 18:641-7.

10. Segesser L, Cox J, Gross J, Lerch R, Gabathuler J, Glassey F, et al. Surgery in primary leiomyosarcoma of the heart. Thorac Cardiovasc Surg. 1986;34:391-4.

11. Putnam JB Jr, Sweeney MS, Colon R, Lanza LA, Frazier OH, Cooley DA, et al. Primary cardiac sarcomas. Ann Thorac Surg. 1991;51:906-10.

12. Reardon MJ, DeFelice CA, Sheinbaum R, Baldwin JC. Cardiac autotransplant for surgical treatment of a malignant neoplasm. Ann Thorac Surg. 1999;67:1793-5.

13. Conklin LD, Reardon MJ. Autotransplantation of the heart for primary cardiac malignancy. Tex Heart Inst J. 2002;29:105-8.

14. Sarjeant JM, Butany J, Cusimano RJ. Cancer of the heart: epidemiology and management of primary tumors and metastases. Am J Cardiovasc Drugs. 2003;3:407-21.

15. Antunes MJ, Vanderdonck KM, Andrade C, Rebelo LS. Primary cardiac leiomyosarcomas. Ann Thorac Surg. 1991;51:999-1001.

16. Pessotto R, Silvestre G, Luciani GB, Anselmi M, Pasini F, Santini F, et al. Primary cardiac leiomyosarcoma: seven-year survival with combined surgical and adjuvant therapy. Int J Cardiol. 1997;60:91-4.

17. Basso C, Valente M, Poletti A, Casarotto D, Thiene G. Surgical pathology of primary cardiac and pericardial tumors. Eur J Cardiothorac Surg. 1997;12:730-7.

18. Agarwal V, Agarwal SK, Srivastava AK, Kaoor S. Primary cardiac tumors: surgical experience and follow-up. Ind Heart J. 2003;55:632-6.

19. Evans BJ, Haw MP. Surgical clearance of invasive cardiac leiomyosarcoma with concomitant pneumonectomy. Eur J Cardiothorac Surg. 2003;24:843-6.

20. Conner WC, Fink GW, McGinnis KM, Alfieris GM. Surgical management of leiomyosarcoma of the mediastinum. Ann Thorac Surg. 2004;77:334-6.

21. Reardon MJ, Walkes JC, Benjamin R. Therapy insight: malignant primary cardiac tumors. Nat Clin Pract Cardiovasc Med. 2006;3:548-53.

22. Loffler H, Grille W. Classification of malignant cardiac tumors with respect to oncological treatment. Thorac Cardiovasc Surg. 1990;38:173-5.

23. Park BJ, Bacchetta M, Bains MS, Downey RJ, Flores R, Rusch VW, et al. Surgical management of thoracic malignancies invading the heart or great vessels. Ann Thorac Surg. 2004;78:1024-30. 